\begin{tabular}{|c|c|c|c|}
\hline $\begin{array}{l}\text { O ROMERIO } \\
\text { IERSITETAS }\end{array}$ & $\begin{array}{l}\text { Escola Superior } \\
\text { de Gestāoe e } \\
\text { Tecnologia } \\
\text { [ipSantarém] }\end{array}$ & 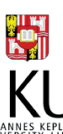 & $\begin{array}{l}\text { ISSN } 2029-7564 \text { (online) } \\
\text { SOCIALINĖS TECHNOLOGIJOS } \\
\text { SOCIAL TECHNOLOGIES } \\
2013,3(1), \text { p. } 177-188\end{array}$ \\
\hline
\end{tabular}

\title{
VERSLO SUBJEKTŲ SANDORIŲ SUDARYMO GALIMYBĖS TAIKANT VIRTUALIŲ TARPININKŲ TEIKIAMAS ELEKTRONINES PASLAUGAS
}

\author{
Dalè Dzemydienè \\ Mykolo Romerio universitetas, Lietuva, daledz@mruni.eu \\ Giedrius Romeika \\ Mykolo Romerio universitetas, Lietuva, giedrius.romeika@gmail.com \\ doi:10.13165/ST-13-3-1-12
}

\section{Santrauka}

Tyrimo tikslas - išanalizuoti sandoriu sudarymo metodus ir priemones, taikant virtualaus tarpininko, teikiančio elektronines paslaugas, atliekamas funkcijas ir pagristi virtualaus tarpininko generuojama pridètine vertę smulkiojo ir vidutinio verslo (SVV) subjektams remiantis sandoriu kaštu teorija.

Metodologija - pasitelkus sudetingu ir daugialypiu santykiu analizes priemones nagrinejamos virtualiu tarpininku paslaugos smulkiojo ir vidutinio verslo subjektams, vertinama ju veikla, išskiriant pridètinés vertés grandinès komponetus ir teikiama nauda. Tyrimo metodika grindžiama mokslinès literatüros analize, apibendrinimo bei palyginamosios analizès metodais.

Praktine reikšme - verslo subjektų (imonių, istaigu, organizaciju) veikla pasiteisina tik tuo atveju, kai yra pelninga. Informacines komunikacines technologijos (IKT) igauna vis didesnę reikšmę mažinant verslo imoniu veiklos kaštus. E. paslaugos, sudarant sandorius, igyja ypatinga reikšmę. Europos Sajungos (ES) vidineje erdvejje veikia daugiau nei 20 milijonu SVV subjektu, ju darbines sritys apima daugiau nei 170 veiklos krypčiu. Tiek vidinè, tiek išorine konkurencija skatina SVV subjektus didinti veiklos efektyvuma. Straipsnyje nagrinejja- 
mos kaštu mažinimo galimybès, susijusios su paslaugomis, kurias teikia virtualūs tarpininkai, turi praktinès reikšmés nacionalinëje tarptautinejje i̇moniu veikloje.

Originalumas/vertingumas - nagrinëjamos kaštu mažinimo galimybès, taikant virtualaus tarpininko funkcijas, ir jo kuriamos pridètinès vertès SVV ükio subjektui pagrindimas.

Raktažodžiai: informacinès technologijos, e. paslaugos, virtualüs tarpininkai, smulkusis ir vidutinis verslas (SVV), paslangu saveikumas.

Tyrimo tipas: analitinis apžvalginis ir teikiamu e. paslaugu atvejo analizé.

\section{Ivadas}

Tokie IT sprendimai kaip elektroninio pašto paskyra, prieiga prie interneto tapo neatsiejamu veiklos atributu, šalies, regiono išsivystymo charakteristikos dedamaja. Skaitmeninès priemonès suponuoja geometrine progresija didejjančią naujų IT sprendimų ir naujų e. paslaugų verslui atsiradimą. Naujų produktų kūrimas ir vystymas yra esminis verslo išlikimo konkurencinèje aplinkoje veiksnys. Ne išimtis ir smulkiojo ir vidutinio verslo subjektai. Ryšys tarp verslo subjekto inovatyvumo bei išorès tarpininkų išnaudojimo yra sudettingas ir daugialypis (Huang et al., 2002; Mazzanti et al., 2007).

Sparčiai didejanti ir nediferencijuota IT produktų ir paslaugų pasiūla apsunkina atskiro smulkiojo ir vidutinio verslo subjekto siekị išsirinkti optimalų IT produktų rinkinị, leisiantị generuoti aukštą pridètinę vertę. Neteisingo sprendimo pasekmès neapsiriboja tiesioginiais finansiniais nuostoliais. Vidinių resursų sąnaudos, prarastas laikas papildo verslo subjekto tiesioginius netekimus, susijusius su netinkamai pasirinktais IT produktais verslo procesui organizuoti. Tiesioginès netekimų pasekmès turi įtakos konkurencinio pranašumo mažèjimui, todèl labai svarbu pasiūlyti tinkamų IT sprendimų pasirinkimo priemones.

Naujos kartos e. paslaugos leidžia verslo įmonėms atsisakyti dalies rutininių, laikui imlių procedūrų ir taip mažinti sandorio kaštus bei klaidų tikimybę (Naujikienè ir Dzemydienè, 2012; Kurmis et al., 2012). Kasdieninių operatyvių rutininių verslo valdymo vidinių ir išorinių funkcijų automatizavimas bei integravimas ir sąveikumas pritaikant informacinius sprendimus bei elektronines paslaugas yra verslo siekiamybè. 75 procentai apklaustų ịmonių vadovų nurode tiesioginị ryšị tarp bendradarbiavimo ir sąveikumo bei ịmonès finansinių veiklos rezultatų (IBM Global CEO Study Team 2006).

Straipsnio tikslas - apžvelgti pateikiamas virtualioje erdvėje veikiančių tarpininkų funkcines galimybes bei skirtingus jų ịvardinimui vartojamus terminus ir parodyti virtualiujų tarpininkų veiklos įtaką smulkiojo ir vidutinio verslo subjekto sandorio kaštams.

Kaip tyrimo rezultatas, apibendrinant virtualaus tarpininko funkcines galimybes, pateikiama virtualaus tarpininko išvystyta daugiakomponentẻ struktūra. İvertinamos e. paslaugos, kurias gali teikti virtualūs tarpininkai IT sprendimais grindžiamoje aplinkoje, nusakant galimą virtualių tarpininkų teikiamų e. paslaugų naudą smulkiojo ir vidutinio verslo subjektams. 


\section{Sandorių kaštų vertinimo palyginimas}

Nepaisant to, jog nuoseklaus sandorių kaštų tyrinèjimas bei nagrinèjimas pradètas dar XX amžiaus ketvirtajame dešimtmetyje ir mokslineje literatūroje egzistuoja nemažai jo apibrèžčių, šiuo metu taip ir nèra vieno visuotinai pripažinto jo funkcinio apibrèžimo (Douglas and Allen, 1999).

Kiekvienos pelno siekiančios organizacijos (verslo įmonès) ịkūrimo tikslas yra aiškiai apibrèžtas jos apibūdinime - pelno siekimas. XVII amžiuje prasidejusios pramonès revoliucijos suformuoti industrializacijos principai darosi vis mažiau reikšmingi XXI amžiuje. Pelno didinimas plečiant gamybos mastus globalioje rinkoje tampa vis sunkiau igyvendinamas. Alternatyva arba išeitis - kaštų mažinimas (optimizavimas). Atsiradus neoinstitucionalizmo teorijai, mikroekonominè analizè buvo išplèsta ị tas ekonomikos sferas ir veiklas, kuriose anksčiau ji buvo nenaudojama. Šios teorijos pradininkas Ronaldas Coase'as parodè, kad realioje tikrovejje egzistuoja transakcinès sąnaudos, ir pasiūlè kiekviename sandoryje nustatyti tarpusavio ryšius, derètis dèl jų ir juos kontroliuoti (Coase, 1937). Iš pradžių R. Coase'as sandorių kaštus įvardijo kaip „naudojimosi rinkos mechanizmu sąnaudas“.

Ilgainiui ši sąvoka igijo platesnę prasmę: ji aprèpė visas sąnaudas, kurios atsiranda verslo bendradarbiavimo srityje, nepriklausomai nuo to, kur jis vyksta (rinkoje tarp atskirų ūkio subjektų, ūkio subjekto viduje ar ūkio subjektų santykiuose su reglamentuojančiomis institucijomis). Vadovaujantis šiuo teiginiu, sandorio kaštus, mokslinèje literatūroje dar vadinamus ,transakcinėmis sąnaudomis“, galima apibūdinti kaip ekonominio bendradarbiavimo sąnaudas, kurios apima sprendimų prièmimo, veiklos planavimo ir jos organizavimo, derybų vedimo, planų keitimo, sutarčiu sąlygų vykdymo priežiūros bei ginčytinų klausimų sprendimo sąnaudas (Stigler, 1961; Shelanski, Omamo, 1998; 1995; Sadoulet, 2000; Vakis, 2003; Wang, 2003; Ciaian, 2009; Henning, 2011; Hockman, 2011; Ohajianya, 2011; Traversac, 2011).

Iš esmès sandorių kaštų apibrèžimus galima suskirstyti ị dvi grupes pagal jų objekto išskyrimą:

Pirmuoju atveju akcentuojamas rinkos sandoris ir kaštais ịvardinamos išskirtinai su sandorio atlikimu susietos išlaidos. Sandorių kaštai yra kaštai, atsirandantys, kai prekès ir paslaugos yra mainomos, tačiau tai nėra kaštai, susiję su prekès ar paslaugos kūrimu (Gatautis et al., 2002).

Antruoju atveju pagrindinis dėmesys yra skiriamas nuosavybès teisèms ir visiems veiksmams, susijusiems su jų įtvirtinimu, apsaugojimu nepaisant to, kada pavojus joms iškyla (Douglas and Allen, 1999).

Sandorio kaštų tyrimas yra vienas iš daugelio ekonominių tyrinėjimų objektų. Sandorio kaštai buvo pradèti tyrinèti siekiant suprasti, kodèl kuriamos komercinès veiklos organizavimo firmos. Sandorio kaštų teorija analizuoja, kaip organizacija turi organizuoti ir igyvendinti savo visapusiško vystymosi veiklą, kad būtų minimizuoti gamybos bei sandorių kaštai. Gamybos kaštai skiriasi, priklausomai nuo organizacijų veiklos mastų, mokymosi ir patirties efektyvumo, lokacijos teikiamų privalumų, itakos, kildinamos iš nuosavybės teisių i patentus, prekybines paslaptis ir kt. Sandorių kaštai taip pat 
yra skirtingi ir apima išlaidas, susijusias su sandorių tarp skirtingų rinkų organizavimu, valdymu ir kontrole. Laikomasi prielaidos, jog bet kokio sandorio atveju organizacija pasirinks efektyviausią ir (arba) pigiausią alternatyvą (Vasiliauskienè ir Venslauskienè, 2012).

\section{Tarpininkavimas ir išorinių paslaugų teikimas}

Nauji verslo subjektai dažniausiai susiduria su ryšių bei išteklių trūkumu (Stinchcombe, 1965). Šie trūkumai ypač išryškèja aukšta konkurencija pasižyminčiose inovatyvių produktų rinkose, kur verslo subjektai turi laiku ir efektyviai prisitaikyti prie greitai kintančių veiklos sąlygų, įvaldyti naujas technologijas, rinkos segmentus bei didinti sprendimų prièmimo greitị (Zhang and Li, 2009). Rinkos spaudimas sandorio dalyviams tiesiogiai turi įtakos sandorio kaštams.

Tiekejas, vartotojas ar jie abu gali sąlygoti sandorių kaštų atsiradimą. Sandorio kaštų efektas pastūmèja pasiūlos ir paklausos kreives atitinkamai ị kairę dėl aukštesnių sandorio kaštų. Kadangi rinka yra nefrikcinè, viena iš šalių norint sudaryti sandorị turi mokèti papildomą sumą.

Sandorio kaštus taip pat gali prisiimti trečia šalis - tarpininkas. Tarpininku ịvardinamas rinkos dalyvis, kuris parduoda prekę, tačiau jos nesukuria ir nevartoja (Gatautis et al., 2002). Pagal mokslinèje literatūroje pateikiamus apibréžimus, tarpininkas nusakomas „kaip rinkos dalyvis, esantis tarp tiekejjo (gamintojo) ir vartotojo (pirkejjo)“. Rinkos tarpininką galima apibūdinti kaip atskirą instituciją, esančią tarp pirkẻjų ir pardavèjų (Cosimano, 1996). Tarpininkas veikia kaip ekonominis agentas, kuris perka iš tiekejjų, o vèliau perparduoda pirkejjams ar padeda pirkejjams ir pardavèjams susitikti ir sudaryti sandorị (Spulber, 1996). Pabrèžtini tarpininko skirtumai nuo tiekejo ir vartotojo. Autorius (Biglaiser, 1993) atskiria tarpininką nuo tiekejo ir nuo vartotojo nagrinèdamas jų tikslus dalyvaujant sandorių rinkoje. Jis paaiškina, kad tiekèjas yra prekès kūrejjas, nes turi nuosavybès teisę ir gali prekę modifikuoti. Tuo tarpu tarpininkas prekès nepakeičia. Tarpininkas skiriasi nuo vartotojo, nes, skirtingai nei vartotojas, tarpininkas negauna naudos turint ar vartojant prekę (Gatautis et al., 2002).

Ūkio pokyčiams intensyvejant, siekiant padidinti įmonių veiklos efektyvumą ir konkurencingumą bei sumažinti kaštus, vis labiau plinta praktika, kuri vadinama išorinių paslaugų teikimu. Europos Parlamento ir Tarybos direktyvoje 2004/39/EB išorinių paslaugų teikimo terminas apibūdinamas kaip „veiklos funkcijų patikèjimas trečiajai šaliai“. Direktyvoje 2006/73/EB angliškasis terminas „outsourcing“ kartais verčiamas „užsakomosios paslaugos“ arba „užsakomujjų paslaugų teikimas“, kartais - „veiklos funkcijų perdavimas išorès paslaugų teikejjui“ (Vasiliauskienè, 2012). Pažymètina, jog užsakomosios paslaugos mokslinèje literatūroje apibūdinamos remiantis skirtingais ìvairių autorių požiūriais, kurios, deja, siaurina pačios koncepcijos suvokimą (Rebernik and Bradač 2010). Pateiktas ir platesnis, holistinis, strateginis požiūrị ị užsakomąsias paslaugas (Giley and Rasheed, 2000). Autoriai užsakomąsias paslaugas apibūdino kaip veiklų (paslaugų) iš organizacijos išorès ịsigijimą, nepaisant to, jog šios veiklos papras- 
tai vykdomos arba gali būti vykdomos pasitelkiant vidinius organizacijos išteklius, jos viduje.

Tarpininkas plačiaja prasme yra jam perduodamų gamintojo arba vartotojo funkcijų perėmèjas, teikiantis užsakytąsias paslaugas. Remiantis šia išvada galima teigti, jog sandorio tarpininkas yra užsakomosios paslaugos teikèjas, kurio veiklą apibūdina Direktyvoje 2006/73/EB nusakytos kryptys.

Principinè tarpininko, veikiančio elektroninių paslaugų rinkoje, funkcijų schema pateikiama 1-ame paveiksle. Tarpininkas gali užtikrinti rinkos sandorio dalyvių rutininių techninių operacijų atlikimą tam naudodamas savo turimą arba išorès paslaugų teikèjo infrastruktūrą (išteklius).

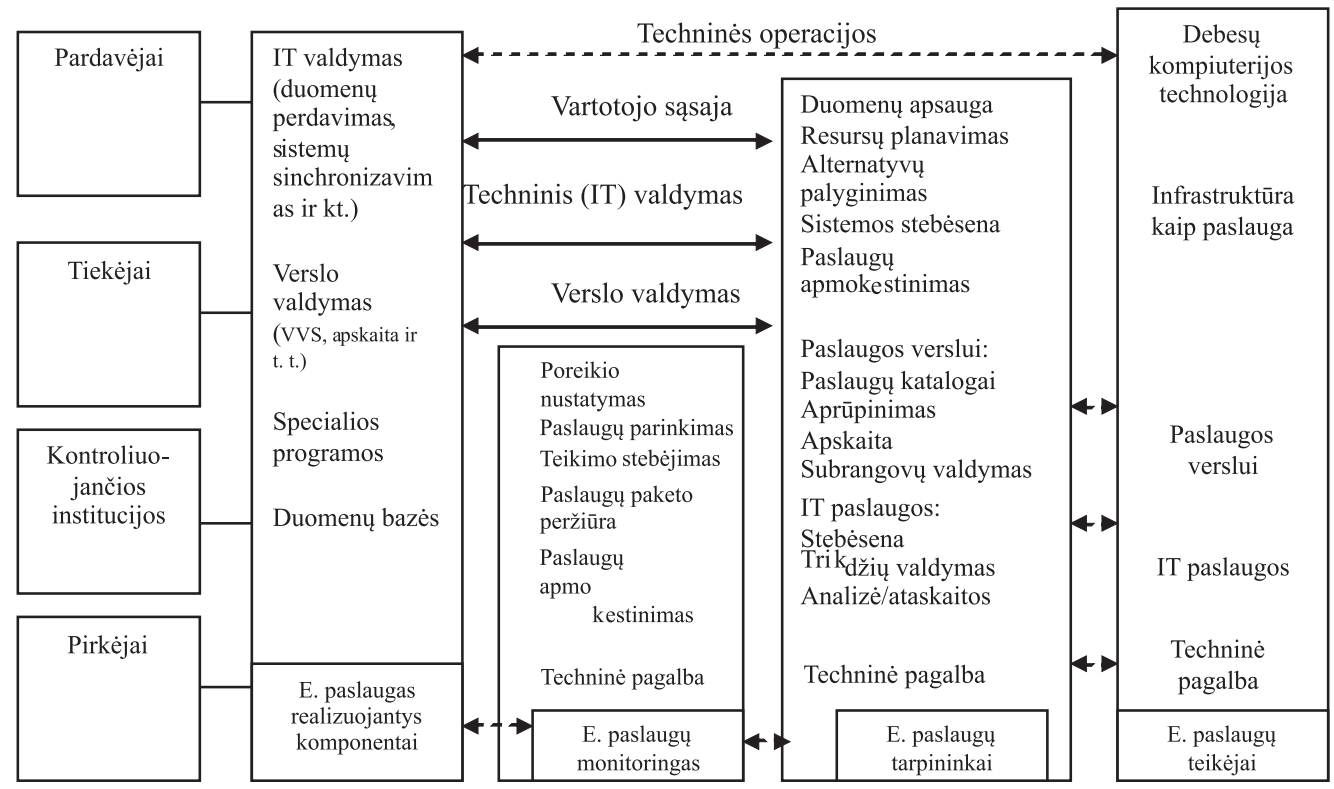

1 pav. E. paslaugų tarpininkų vaidmuo IT sprendimais grindžiamoje aplinkoje

\section{Virtualaus tarpininkavimo procesas ir jo įtaka sandorio kaštams}

Kai kuriuose tarpininkavimo modeliuose skiriami virtualieji tarpininkai, kurių atsiradimą suponavo ūkinès veiklos, jos operacijų vykdymas internete. Išskiriama e. tarpininkų vertẻ palengvinant veiklą sparčiai besiplečiančiose e. rinkose. Virtualieji (elektroniniai) tarpininkai taip pat generuoja tinklo paslaugų pokyčius, formuoja inovacinius efektus (Saarkar, 1995; Beam, 1999; Buxmann and Gebauer, 1998).

Elektroninių užsakomujų paslaugų vykdymą pasitelkiant virtualaus tarpininkavimo procesą galima apibūdinti kaip internetinejje erdvejje susiformavusị ryšị ar santykius tarp reikalingų intelektualių paslaugų ieškančių subjektų bei jas teikiančių ir siūlančių laboratorijų (Vasicek, 2000). 
Visus verslo subjektus, kurie organizuoja informacijos apie prekes ir paslaugas apsikeitimą naudodamiesi elektroniniais marketingo kanalais, galima vadinti virtualiaisiais tarpininkais (Gupta and Woodside, 2006).

Virtualiu tarpininku galima ịvardinti „kažką“ nepriklausomą, administruojantị intelektualų tarpininkavimo sprendimą, sukuriantị pridètinę vertę tiek pirkẻjui, tiek tiekẻjui atliekant sandorị virtualioje rinkoje (Fairchild, 2006).

Apibendrinant virtualiuosius tarpininkus galima nusakyti kaip virtualų įrankị, kuris IT galimybėmis sukuria sandorio dalyvių pavestas funkcijas administruojančią struktūrą (2 pav.).

Tarpininkai konkuruoja su kitais rinkos dalyviais, kurie gali pardavinèti tokią pačią prekę ar paslaugą. Konkurencija yra viena iš prielaidų, leidžiančių pagrịsti tarpininko generuojamą pridètinę vertę sandorio dalyviams - mažèjančius sandorio kaštus (Porter, 2000; Gatautis et al., 2002).

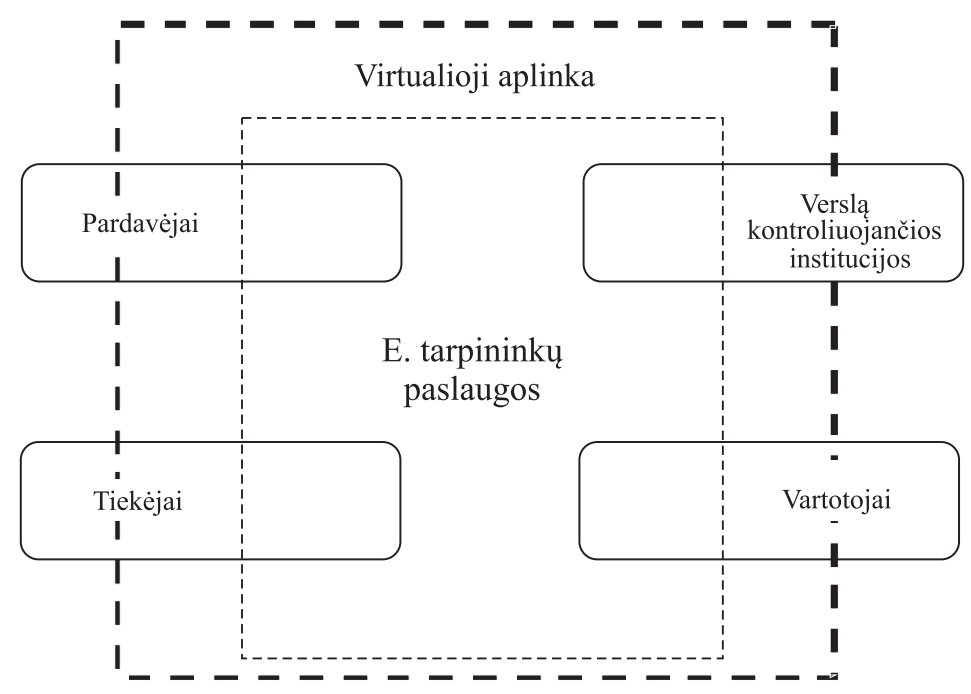

2 pav. E. tarpininkų vieta sandorio atlikimo procese

Produkto mainų procese dalyvaujant tarpininkui atsiranda objektyvios priežastys sandorio kaštų mažèjimui:

- Specializacija apsibrèžtoje veiklos srityje sudaro prielaidas gilinti atliekamo proceso išmanymą ir didinti jo efektyvumą;

- Masto efekto išnaudojimas, galimas atliekant tą patį tarpininkavimo procesą vis didejančiam gamintojų ir vartotojų skaičiui;

- Tikslinès investicijos ị proceso tobulinimą, kurių negali sau leisti gamintojas ir/ ar vartotojas dèl savo veiklų diversifikacijos;

- Sinergija, atsirandanti pritraukiant papildomus aptarnaujamus gamintojus ir/ar vartotojus. 
Šalia kiekybiniais rodikliais išmatuojamų tarpininkavimo veiklos privalumų skiriama ir kokybinè tarpininkavimo nauda atskiram (ypač naujam SVV statusą atitinkančiam) verslo subjektui. Tarpininkų, kaip naujo verslo patikimumo ir garanto vaidmeni atliekančios institucijos, svarba ịvardinta Zhang ir Li (2009) darbe. Naujai susikūręs verslo subjektas arba ị apibrěžtą laikotarpi orientuotas laikinasis darinys dažniausiai susiduria tiek su išteklių trūkumu, tiek su veiklos istorija grịstos reputacijos nebuvimu.

Išorinių tarpininkų teikiamų paslaugų naudą būtų galima pagrịsti pagal literatūroje aptinkamus šaltinius. Dažniausiai ši nauda pagrindžiama remiantis veiklos kaštų - naudos teorija (Rebernik and Bradač, 2010). Būtent nuo veiklos kaštų dydžio priklauso, kurią veiklos struktūrą - paremtą vidiniais resursais (hierarchinę) ar naudojantis išorinių tarpininkų paslaugomis (rinkos), pasirinks pelno siekianti organizacija.

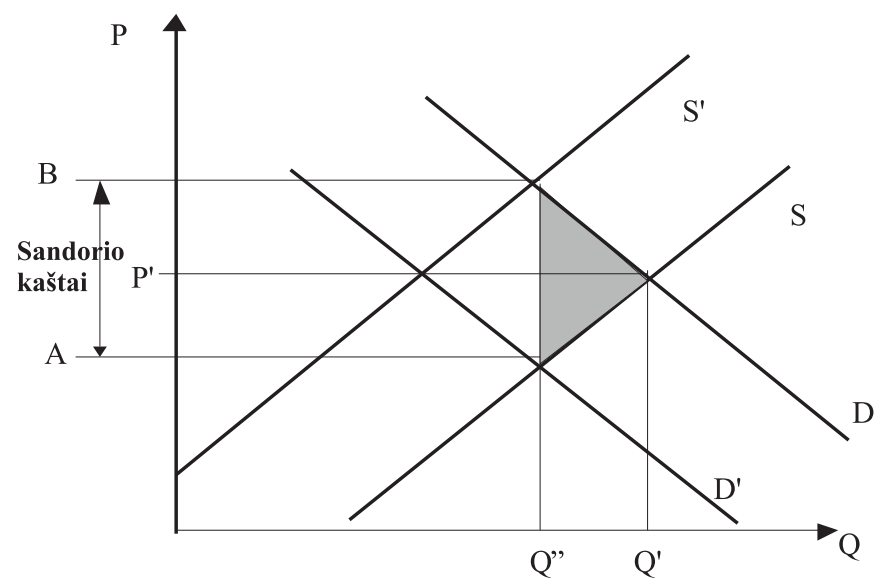

3 pav. Sandorio kaštai tarpininkų rinkoje pagal Gatautis et al. (2002)

Rinkos mainų situacija dalyvaujant tarpininkui pavaizduota 3 pav. Naudojamos dvi kainos: A - už kurią tarpininkas nuperka prekę, bei B - kaina, už kurią tarpininkas tikisi parduoti prekę. Kaina $\mathrm{P}^{\text {‘ }}$ - pasiūlos ir paklausos pusiausvyros kaina (E) monopolinès konkurencijos sąlygomis. Kainų A ir B skirtumas, pavaizduotas 3 pav., yra paklausospasiūlos pasiskirstymo funkcijos išraiška, ir tai gali būti laikoma sandorio kaštais mainams rinkoje įvykti (Gatautis et al., 2002).

Sudètingose situacijose išryškèja tarpininko paslaugų teikiami privalumai (Hargadon and Sutton, 1997; Howells, 2006; Wolpert, 2002). Verslo subjektas pirkdamas tarpininko paslaugas (buhalterinès apskaitos, darbuotojų paieškos, teisines konsultacijas, komercinį bei technologinį asistavimą) automatiškai naudojasi tarpininko resursais, apimančiais jo ryšius, reputaciją, žinias (Wolpert, 2002), taip ženkliai sustiprindamas savo pozicijas konkurencinejje kovoje. 


\section{Elektroninių paslaugų galimybès užtikrinti virtualaus tarpininko funkcijas}

Ryškų poveikį sandorio kaštams gali daryti sandorių vykdymas elektroninės komercijos industrijoje. Tiesioginius ir netiesioginius kaštus gali sumažinti vis dažnėjantys sandoriai (dèl atvirų standartų), neapibrèžtumo sumažèjimas (teikiant vis daugiau informacijos, susijusios su sandorių specifika), turto specifikos mažinimas (Vasiliauskienè ir Venslauskienè, 2012).

Naudojantis elektronine komercija sandorio kaštai gali sumažèti (Claver et al., 2002; Gatautis et al., 2002) dèl sumažėjusių:

- informacijos paieškos kaštų;

- koordinavimo kaštų;

- atsiskaitymo proceso išlaidų.

Interneto teikiamos paslaugos ir jų îvairovè yra priemonès, kurios turès įtakos hierarchinių įmonių organizacinio valdymo pertvarkymui ir paskatins naujų rinkos dalyvių atsiradimą. Tai ypač pasitvirtina tarpininkavimo atvejais.

Nuo 1980 m. sparčiai besiplètojantis IT naudojimas verslo procesuose suformavo atskirą verslo procesų evoliucijos kryptị (Harmon, 2010), kurioje atsiradę atskiri verslo valdymo modeliai, koncepcijos, įrankiai bei sprendimai suformavo prielaidas šiuo metu taikomų elektroninių paslaugų atsiradimui.

Elektronines paslaugas teikiančių tarpininkų privalumams priskiriamas ne tik kiekybiniais rodikliais išmatuojamą kaštų minimizavimas, bet ir kokybinių sandorio rodiklių užtikrinimo galimybe (Kiauleikis et al., 2011). Autorių teigimu, elektroninès paslaugos gali pakeisti kasdienes verslo sandorio procedūras (pvz., užsakymo pateikimaspriemimas) bei formalizavimo pagrindu optimizuoti atskirus verslo sandorio etapus (pvz., skundų pateikimą bei nagrinèjimą). Šalia to išskiriamas sandoryje naudojamos informacijos bei duomenų srautų patikimumas ir klaidos tikimybès sumažèjimas operacijos patikejimo specializuotam tarpininkui atveju.

Pagrindiniai virtualaus tarpininko skirtumai lyginant su tradicinio tarpininko funkcijomis yra:

- Fizinès veiklos (paslaugos teikimo) vietos neapibrezžtumas. Paslauga teikiama elektroninèmis ryšio priemonėmis, virtualioje erdvejje ir jai nebūtinas fizinis adresas;

- Aukštas paslaugos administravimo standartizacijos lygis, užtikrinantis masto efekto išnaudojimo galimybes;

- Teikiama paslauga yra informacijos valdymo veikla;

- Veikla pasižymi aukštu internacionalizacijos lygiu arba potencialu.

Virtualiujų tarpininkų teikiamas e. paslaugas galima klasifikuoti pagal:

- naudojimą atskiruose sandorio ịgyvendinimo etapuose (informacijos paieškos, derybų, kokybės ịvertinimo, nuosavybės teisių apsaugos, oportunistinio elgesio);

- veiklos organizavimo etapus (informacijos paieška, sandorio koordinavimas, sandorio kontrolè); 
- pasirinktų sandorio veiklų tobulinimą (finansinès informacijos integravimas, klientų užsakymų informacijos integravimas, gamybinių procesų gerinimas ir standartizavimas, laikomų atsargų mažinimas, personalo valdymo standartizavimas);

- taikomas technologijas (pvz., programavimo architektūros pasirinkimą).

Nagrinëjant e. verslo modelius, yra siūloma e. verslą išskaidyti ị tokius modelius kaip: e. komercija, e. servisas, e. marketingas, e. verslo kontaktai, e. projektų vadyba, e. biuro darbo organizavimas, žmogiškujų išteklių e. vadyba, e. logistika (Paliulis, 2007).

Virtualių tarpininkų teikiamos e. paslaugos didina verslo subjektų tarpusavio bendradarbiavimo ir sąveikumo lygi (Kiauleikis et al., 2011). Bendradarbiavimo ir sąveikumo paslaugos yra naujas žingsnis, plečiant informacinių technologijų naudojimą tinklinèse įmonėse. Organizacijų tinklų atsiradimas, įmonių tiekimo grandinių savarankiškumo didèjimas dèl išorinių paslaugų naudojimo keičia tradicinị požiūrị ị vertès grandinę.

Standartizuotos tiekimo grandinės modelyje (SCOR), pateiktame darbuose (Bolsstroff and Rosenbaum, 2007; Poluha, 2007), naudojamas tarptautinès Tiekimo grandinès tarybos rekomenduojamas modelis, ịvertinantis proceso vertę nuo tradicinès tiekimo grandinès iki paslaugų teikimo ir pasižymintis išskiriamais antrojo bei trečiojo lygio procesais, apibrèžiančiais organizacijos savarankiškumo bei bendradarbiavimo galimybes. Siekiančios bendradarbiauti organizacijos, vykdydamos savo tiekimo grandinès veiklas, galètų pasinaudoti tokia pačia SCOR principais grịsta struktūra ir lengviau vykdyti bendradarbiavimo procesą tuo pat metu neprarasdamos individualumo bei lankstumo naudodamosi išorinių e. tarpininkų teikiamomis paslaugomis.

\section{Išvados}

Veiklos efektyvumo didinimas tradicinès plètros būdu tampa neịmanomas be elektroninių paslaugų ir virtualių priemonių naudojimo. Atskiram ūkio subjektui, ypač priskiriamam smulkaus verslo subjekto statusui, alternatyva veiklos rodiklių gerinimui plečiant veiklą yra sąnaudų kaštų mažinimas. Sąnaudų kaštų teorija įrodinèja, jog kiekvienas verslo subjektas, siekiantis ūkinès naudos, privalo minimizuoti savo veiklos kaštus, tokiu būdu didindamas pelną. Vienas iš kaštų mažinimo būdų yra specializuotų tarpininkų ịtraukimas ị sandorị. Išanalizavus tarpininkų veiklos generuojamą vertę galima teigti, jog tarpininkas dèl specializacijos teikiamų pranašumų efektyviau išnaudoja turimus resursus bei dalinasi dẻl to išauginta pridètine verte tiek su gamintoju, tiek su vartotoju per jų sandorio kaštų mažinimą.

IT paplitimas bei taikymas leidžia didžiają dali sandorio procedūrų perkelti ị virtualią erdvę. Virtualioje erdvèje teikiamos e. paslaugos verslui pasižymi galimybe generuoti tinklo efektus taip išauginant savo efektyvumą, pasiekiamumą bei papildomos vertès generavimą. Šio reiškinio išdava galima laikyti straipsnyje apibrèžiamus virtualiuosius tarpininkus, teikiančius e. paslaugas verslui. Išnaudodami siauros specializacijos derinimo su masto efektu galimybę virtualūs tarpininkai gali generuoti (kurti) paslaugas, pasižyminčias minimaliomis sąnaudomis bei aukšta pridètine verte. Atsiranda prielaidos 
sinergijos efekto išnaudojimui, tinklinėms organizacijoms kurtis, tuo pat metu orientuojant atskiro ūkio subjekto ar jų grupès veiklą ị atskiras projektines užduotis, taip didinant veiklos efektyvumą bei visuotinès naudos gavimą.

Norintis sėkmingai funkcionuoti globalios konkurencijos bei informacijos prieinamumo aplinkoje ūkio subjektas, ypač valdantis ribotus resursus (dauguma tokių turi SVV subjektų statusą), turètų naudotis virtualių tarpininkų teikiamomis e. paslaugomis. E. pašto naudojimas, informacijos paieška internete, naudojimasis specializuotais portalais ar e. ryšio priemonėmis daugumai verslo subjektų yra neatskiriama rutininių operacijų dalis. Konkurencinị pranašumą gali suteikti rutininių verslo operacijų, susijusių su sandorio atlikimu, optimizavimas jas patikint virtualiems tarpininkams, teikiantiems bendradarbiavimą bei sąveikavimą didinančias paslaugas.

Tinkamai pasirinkdamas išorines e. paslaugas verslo subjektas gali optimizuoti savo tiekimo grandinę rasdamas tinkamiausią balansą tarp autonomiškumo (išsaugodamas savo identitetą, išskirtinumą) bei bendradarbiavimo (sumažindamas sandorių kaštus). Šių dviejų charakteristikų suderinimas leistų verslo subjektui užsitikrinti veiklos lankstumą, didinantị pranašumą konkurencinėje kovoje.

\section{Literatūra}

Benguria, G. and Santos, I. 2008. SME Maturity, Requirement for Interoperability. I-ESA Conference. Berlin, 2008.

Bresnahan, T.; Brynjolfsson, E.; Hitt, L. M. 2002. Information Technology, Workplace Organization and the Demand for Skilled Labor: Firm-level Evidence. Quarterly Journal of Economics, 117(1): 339-376.

Carr, N. G. 2003. IT Doesn't Matter. Harvard Business Rewiew, 5: 5-12.

Fairchild Alea, M. 2006. Information Technology \& Management, 7 (4): 266-298.

Forbat, J. 2007 Entrepreneurship: The Seeds of Success, Harriman House, 2007.

Fink, M. and Kraus, S. 2010 The Management of Small and Medium Enterprises. Routledge, 2010.

Gatautis, R.; Neverauskas, B.; Snieška, V. 2002. Interneto įtaka sandorių kaštams ir tarpininkavimo paslaugoms. Inžineriné ekonomika, 3: 125-136.

Gupta, S. and Woodside, A. 2006. Journal of Business-to-Business Marketing, 13(4): 256-279.
IBM Global CEO Study Team. Expanding the Innovation Horizon: The Global CEO Study 2006. IBM Global Services.

Kiauleikis, V.; Romeika, G.; Kiauleikis, M.; Morkevičius, N. 2011. Collaboration and Interoperability services vs. Traditional Communication Means. Mokslas ir edukaciniai procesai, 3(16): 62-75.

Koellinger, Ph. 2008. The relationship between technology, innovation, and firm performance - Empirical evidence from e-business in Europe. Research policy, 37: 458-499.

Kurmis, M.; Dzemydienè, D.; Andziulis, A. 2012. Investigation of data transfer capabilities for heterogeneous service support in critical mobile objects communication situations. Databases and information systems: Tenth International Baltic Conference on Databases and Information Systems: Local Proceedings, Materials of Doctoral Concortium. Edited by Albertas Čaplinskas, et al.; Lithuanian Academy of Sciences, Vilnius University, Lithuanian Computer Society. Vilnius: Žara, 2012, p. 154-161. 
Lakis, A. ir Namiotko, V. Transakcinių sąnaudų vertinimo metodologiniai aspektai. Management theory and studies for rural business and infrastructure development. 2012, 1 (30): 120-144.

Linder, J. C. and Cantrell, S. 2001. Business Models: Cautionary Tales. Accenture Outlook Journal [interaktyvus]. [žiūrèta 2012-07-15]. <http://www.accenture.com/ Global/Research_and_Insights/Outlook/By_ Alphabet/InFatal.htm>.

Mazzanti, M.; Montresor, S.; Pini, P. Outsourcing and innovation: Evidence for a local production system of Emilia-Romagna. INNOVATION: Management, Policy \& Practice. 2007, 9 (3-4): 211-258.

Naujikienè, R. ir Dzemydienè, D. 2012. Evaluation of public e-services and information technology accessibility in different social groups. Social technologies, 2(2): 335-348.

Paliulis, N. K. 2007. E. verslo plettros tyrimai: ataskaita. VGTU, 2007.

Porter, M. E. 2000. Location, Competition, and Economic Development: Local Clusters in a Global Economy. Economic Development Quarterly, 2000, 14(1): 15-34.

Peppard, J. and Rylander, A. From Value chain to Value Network. Insights for Mobile Operators. European Management Journal. 2006, 24(2-3): 128-141.

Rappa, M. 2010. Business Models on the Web. [interaktyvus]. [žiūrèta 2012-07-01]. <http:// digitalenterprise.org/models/models.html $>$.

Razak, R. A., et al. 2009. The Scenarios of Enterprise Architecture in Malaysian Organizations. Knowledge Management and Innovation in Advancing Economies: Analyses and Solutions. Marrakech, Morocco.
Santos, I.; Schuster, S.; Vergara, M.; Alonso, J. 2007. Assessing the Readiness for Enterprise Collaboration and Enterprise Interoperability COIN Consortium (IP216256). Collaboration and Interoperability for Networked Enterprises. Annex I Description of Work, 2007.

Stanley, J. and Briscoe, G. The ABC of Digital Business Ecosystems, Communications Law [interaktyvus]. [žiūrèta 2012-07-04]. < http:// arxiv.org/ftp/arxiv/papers/1005/1005.1899. pdf $>$.

Tiernan, C. and Pepprard, J. Information Technology: Of Value or A Vulture? European Management Journal. 2004, 22(6): 609-623.

Vasiliauskienè, L. ir Venslauskienè, D. Statistical valuation of different kinds of outsourcing activities. Economics and Management. 2012, 17(4): 1443-1448.

Vasicek, T. Bringing Science Up To Next Speed. Scientific Computing and Instrumentation [interaktyvus] 20001101 [žiūrèta 2013-0110]. <www.scimag.com>.

Vermeulen, P. A. M. Uncovering Barriers to Complex Incremental Product Innovation in Small and Medium-Sized Financial Services Firms. Journal of Small Business Management. 2005, 43(4): 432-452.

Vom Brocke, J. and Rosemann, M. Handbook on Business Process Management 1: Introduction, Methods and Information Systems. Springer, 2010.

Zhang, Y. and Li, H. Innovation Search of New Ventures In A Technology Cluster: The Role of Ties With Service Intermediaries. Strategic Management Journal. 2010, 31: 88-109. 


\title{
OPPORTUNITIES OF E-SERVICE PROVIDING INTERMEDIARIES IN TRANSACTIONS OF BUSINESS SUBJECTS
}

\author{
Dalè Dzemydienè \\ Mykolas Romeris University, Lithuania, daledz@mruni.eu \\ Giedrius Romeika \\ Mykolas Romeris University, Lithuania, giedrius.romeika@gmail.com
}

Summary. The aim of this research: to analyze the transaction methods and tools through a virtual intermediary providing electronic services and functions based on virtual agent generated added value to small and medium-sized business enterprises (SMB) based on transaction cost theory.

Used methodology: through a complex and multi-faceted relationship analysis examining the virtual intermediary services to small and medium-sized enterprises, evaluating their performance, highlighting the added component of the value chain and benefits. The research methodology is based on the scientific literature, generalization and comparative analysis.

The practical significance: the activities of business enterprises (corporations, organizations) are profitable, if usage of Information and Communication Technologies (ICT) is effective. ICT is becoming increasingly important in reducing business operating costs. E-services used in business transactions acquire special significance. European Union (EU) in the inner space in more than 20 million of SMEs and their work areas include more than 170 activities. Both internal and external competition encourages SME operators to increase operational efficiency. The article analyzes the cost-cutting options related to services provided by virtual intermediaries and has practical significance in the national and international companies.

Originality/value: looking at cost reduction opportunities through a virtual agent functionality and value-added SME operator justification.

Keywords: information technology, e-service, virtual agents, small and medium business $(S M B)$, service interoperability. 